\title{
ANALISIS ELEMEN ELEMEN BRAND EQUITY PADA PRODUK MINUMAN TEH DALAM KEMASAN DI KOTA DENPASAR
}

\author{
I Putu Satya Wijaya ${ }^{1}$ \\ I Gusti Ayu Ketut Giantari²
}

\author{
${ }^{1,2}$ Fakultas Ekonomi dan Bisnis Universitas Udayana, Bali, Indonesia \\ email: satyawiwis@gmail.com
}

\begin{abstract}
ABSTRAK
Penelitian ini bertujuan untuk mengetahui nilai brand equity atau ekuitas merek dari masing-masing produk. Penelitian ini dilakukan di Kota Denpasar dengan menggunakan kuesioner. Ukuran sampel yang diambil sebanyak 100 orang responden dengan metode purposive sampling. Data dikumpulkan dengan menyebarkan kuesioner untuk mengukur 20 indikator. Teknik analisis yang digunakan adalah analisis statistik deskriptif. Hasil penelitian ini menemukan bahwa Teh Botol Sosro memiliki keunggulan pada elemen brand awareness dengan pencapaian pada indikator top of mind sebesar $62 \%$. Untuk elemen brand loyalty, konsumen yang berkomitmen untuk terus mengkonsumsi Teh Botol Sosro lebih sebanyak 16\%. Sedangkan Teh Pucuk Harum memiliki keunggulan pada elemen brand association yaitu cita rasa yang tinggi, merek terkenal, volume isi banyak dan harga terjangkau dan untuk indikator perceived quality merek Teh Pucuk Harum memiliki kinerja dan harapan yang baik dengan rata-rata kinerja sebesar 4,37 dan harapan dengan rata-rata sebesar 4,77 yaitu pada indikator rasa yang enak dan kualitas yang baik.
\end{abstract}

Kata Kunci: brand equity, brand awareness, brand association, perceived quality, brand loyalty.

\begin{abstract}
This study aims to determine the value of brand equity or brand equity of each. This research was conducted in Denpasar City by using questionnaire. Sample size taken as many as 100 respondents with purposive sampling method. Data were collected by distributing questionnaires to measure 20 indicators. The analysis technique used is descriptive statistical analysis. The results of this study found there is Bottle Tea Sosro has an advantage on the brand awareness element with achievement in the top of mind indicator of $62 \%$. For the element of loyalty, consumers are committed to continue consuming Sosro Bottle Tea more as much as 16\%. Meanwhile, Pucuk Harum Tea has an advantage on brand association element that is high taste, famous brand, large volume of content and affordable price and for perceived quality indicator of brand shoot Harum has a good performance and expectation with average performance of 4.37 and hope with an average of 4.77 on the indicator of good taste and good quality.
\end{abstract}

Keyword: brand equity, brand awareness, brand association, perceived quality, brand loyalty. 


\section{PENDAHULUAN}

Pada saat ini teh masih menjadi daya tarik tersendiri untuk di konsumsi oleh masyarakat Indonesia. Teh merupakan salah satu minuman yang digemari masyarakat Indonesia sejak dahulu karena dipercaya mampu memberikan manfaat untuk kesehatan dan kecantikan. Teh adalah minuman yang dihasilkan dari pengolahan daun tanaman teh. Pusat Data dan Sistem Informasi Pertanian memproyeksikan bahwa konsumsi teh di Indonesia pada tahun 2017 sebanyak 113.064 ton, dengan data tersebut membuat banyak perusahaan berlomba untuk memproduksi minuman tehyang dapat di konsumsi oleh mayarakat. Banyak jenis teh dalam kemasan bermunculan diantaranya teh hijau, teh rasa buah, teh rasa madu, tehberkarbonasi, teh melati dan teh dengan kadar gula yang sedikit (less sugar). Berikut merupakan daftar perusahaan yang memproduksi minuman teh dalam kemasan di Indonesia.

\section{Tabel 1}

Perusahaan yang memproduksi teh dalam kemasan tahun 2017

\begin{tabular}{ccc}
\hline No & Nama Perusahaan & Nama Produk \\
1 & PT. Sinar Sosro & Teh Botol Sosro, Fruit Tea, Tebs \\
2 & PT. Mayora Indah Tbk & Teh Pucuk \\
3 & PT. Coca-Cola Indonesia & Freshtea \\
4 & PT. Orang Tua Group & Teh Gelas \\
5 & PT. Ultrajaya Milk Industry & Teh Kotak \\
\hline
\end{tabular}

Sumber: Rheisiki, 2016

Besarnya proyeksi terhadap konsumsi teh tahun 2017 membuat banyak perusahaan termotivasi untuk mampu bersaing dan turut menguasai pangsa pasar seperti Tabel 1 yang memperlihatkan perkembangan perusahaan teh di Indonesia. Pergerakan dalam dunia pemasaran yang sangat dinamis, ditambah dengan perkembangan perilaku konsumen dari masa ke masa, menuntut produsen harus 
lebih adaptif dalam melakukan strategi pemasaran yang digunakan agar dapat diterapkan dengan tepat dan sesuai dengan kondisi pasar pada saat itu. (Aditya dan Wardana, 2017). Banyaknya konsumsi masyarakat terhadap minuman teh membuat banyak perusahaan berlomba untuk membuat produk baru yang menarik minat konsumen, lalu secara cepat dapat membaca adanya peluang untuk masuk ke pasar yang kompetitif dan dapat menguasai pasar.Perusahaan yang masuk ke lingkungan kompetitif otomatis sudah siap untuk bersaing dengan perusahaan lainnya dan terus berinovasi menciptakan minuman dalam kemasan dengan berbagai manfaat yang akan dirasakan konsumen. Apabila suatu produk telah memiliki ciri khas tersendiri, maka akan dapat mempermudah persaingan produk tersebut (Tan Teok Ming et al., 2012). Data dari Top Brand Award tahun 2017, menunjukkan produk-produk teh dalam kemasan yang mampu bersaing dan memiliki kualitas yang baik di Indonesia.

\section{Tabel 2}

Teh dalam kemasan siap minum Top Brand Award 2017

\begin{tabular}{lcc}
\multicolumn{1}{c}{ Merek } & Tbi & Top \\
\hline Teh Botol Sosro & $32.0(\%)$ & Top \\
Teh Pucuk Harum & $22.7(\%)$ & Top \\
Teh Gelas & $12.6(\%)$ & Top \\
Ultra Teh Kotak & $6.8(\%)$ & \\
Frestea & $6.3(\%)$ & \\
\hline \multicolumn{2}{l}{ Sumber: www.Top Brand Award.com }
\end{tabular}

Dari data Top Brand tahun 2017 mengenai market share produk teh dalam kemasan diatas dapat dilihat bahwa ada 2 produk dengan merek berbeda, yang mengalami persaingan sangat ketat, yakni Teh Botol Sosro dan Teh Pucuk Harum keduanya mampu bersaing di pasaran saat ini. Teh Botol Sosro sudah mampu 
menguasai pasar sejak tahun 2014, hal tersebut dibuktikan dengan pencapaian yang diraih Teh Botol Sosro sebesar 51\% pada tahun 2014, namun pencapaian tersebut menurun setiap tahunnya seiring adanya pesaing yang terus melakukan inovasi dan menciptakan produk baru, pesaing berat Teh Botol Sosro saat ini yaitu Teh Pucuk Harum. Teh Pucuk Harum mampu meningkatkan penjualannya berkat adanya produk baru yakni teh melati dalam kemasan. Dengan adanya produk baru tersebut mengakibatkan penurunan pencapaian dari Teh Botol Sosro menjadi 32\% pada tahun 2017. Sementara pesaing Teh Botol Sosro yakni Teh Pucuk Harum mengalami peningkatan drastis mulai tahun 2017. Pada tahun 2014 Teh Pucuk Harum hanya mampu mencapai 5,1\% namun pada tahun 2017 menjadi 22,7\%. Dengan data tersebut dapat dilihat secara jelas perusahaan-perusahaan terus bersaing untuk menguasai pangsa pasar yang ada.

Pada hakikatnya, merek dapat mengidentifikasi penjual atau pembuat. Merek merupakan sebuah janji penjual untuk secara konsisten memberikan keistimewaan, manfaat, dan jasa tertentu kepada pembeli. Jadi sudah seharusnya merek menjadi suatu identitas dari produk dan perusahaan tersebut. (Garlina, 2014) menyatakan bahwa merek juga memiliki nilai yang tinggi, nilai prestasi yang baik, memiliki kekuatan dan ekuitas (brand equity) yang besar. (Darmawan dkk., 2016) menyatakan brand yang memberikan nilai lebih tinggilah yang akan selalu menjadi pilihan konsumen. Merek yang kuat sudah pasti dapat menguasai pasar, karena kekuatan merek merupakan asset perusahaan yang paling bernilai, yang dapat digunakan untuk memprediksi kelangsungan hidup perusahaan. (Shabbir, 2014). 
Teh Botol Sosro dan Teh Pucuk Harum merupakan dua produk teh dalam kemasan siap minum yang terbaik saat ini. Kedua produk ini memiliki brand yang terkenal dengan memperhatikan setiap elemen dari brand equity sebagai dasar perkembangan produknya saat ini hingga dikenal oleh konsumen. Terbukti kedua produk teh dalam kemasan ini mampu berada dipuncak kategori produk teh dalam kemasan siap minum. Namun tentu saja ada perbedaan keunggulan dari setiap elemen brand equity yang ada baik dari Teh Botol Sosro maupun Teh Pucuk Harum.

Menurut (Aaker, 2013:204) memaparkan bahwa brand equity merupakan serangkaian aset dan keterpercayaan merek yang terkait dengan merek tertentu, nama, simbol, yang mampu menambah atau mengurangi nilai yang diberikan oleh sebuah produk bagi konsumen. Brand equity merupakan aktiva tak terwujud yang memiliki peranan penting dan dapat memberikan keunggulan kompetitif bagi perusahaan (Shahin et al., 2012). Brand equity mampu berperan sebagai identitas merek seperti logo, simbol, merek dagang, dan slogan untuk dapat mengidentifikasi dan melihat bagaimana pengaruh produk terhadap konsumen (Alam et al.,2016). Dalam buku (Aaker, 2013:204) menyebutkan ada 4 elemen yang terdapat dalam brand equity yakni brand awareness, perceived quality, brand association dan brand loyalty

Kualitas yang dirasakan (perceived quality) adalah persepsi konsumen terhadap keseluruhan kualitas atau keunggulan suatu produk dengan sesuatu yang diharapkan (Durianto dkk., 2004:96). Loyalitas merek akan berdampak baik bagi konsumen karena akan timbul rasa ingin membeli kembali terhadap suatu merek 
produk tertentu, walaupun dihadapkan pada banyak alternatif merek produk pesaing yang menawarkan karakteristik produk yang lebih unggul (Aaker, 2013:206). Ukuran ini mampu memberikan gambaran tentang mungkin tidaknya seorang pelanggan beralih ke merek produk lainnya, terutama jika merek tersebut terdapat suatu perubahan, baik menyangkut harga ataupun atribut lain (Durianto dkk., 2004:126).

Berdasarkan survei awal yang telah dilakukan terkait dengan brand equity Teh Botol Sosro dan Teh Pucuk Harum terhadap 20 responden yang dimana 13 responden menyatakan Teh Botol Sosro lebih unggul dibanding Teh Pucuk Harum. Penelitian mengenai analisis elemen brand equity juga sebelumnya sudah pernah dilakukan oleh (Touli dkk., 2013), (Gumilang dkk., 2013), (Widiananta dan Wardana, 2016). Penelitian (Bakhtiar, 2015) menyatakan produk kartu simpati memiliki tingkat brand awareness yang tinggi yang mampu membentuk piramida terbalik, memiliki asosiasi paling banyak diantara kartu prabayar yang lainnya, memiliki loyalitas paling tinggi dan persepsi konsumen yang baik terhadap kartu simpati. Penelitian (Touli, 2013) menyatakan terdapat perbedaan antara semua elemen dari brand equity dari beberapa bank negeri di Iran menurut konsumen. (Aristyani dan Yasa, 2013) menyatakan dari empat elemen brand equity, terdapat tiga elemen, yaitu: brand awareness, brand association, dan brand loyalty tidak menunjukkan perbedaan yang signifikan antara shampoo merek Sunsilk dengan Pantene. Hanya satu elemen yang menunjukkan perbedaan signifikan yaitu perceived quality. Sedangkan menurut penelitian yang dilakukan oleh (Arora \& Neha, 2016) mengenai faktor penentu ekuitas merek berbasis 
pelanggan antara bank umum dan swasta mendapatkan hasil berbeda yaitu tidak ada perbedaan dari ke empat elemen brand equity dari bank umum dan swasta di India.

Tujuan dalam penelitian ini adalah untuk menjelaskan brand equity pada produk minuman teh dalam kemasan merek Teh Botol Sosro, Untuk menjelaskan brand equity pada produk minuman teh dalam kemasan merek The Pucuk Harum, dan untuk menjelaskan perbedaan elemen brand euity antara produk minuman teh dalam kemasan merek Teh Botol Sosro dan merek Teh Pucuk Harum.

Penelitian ini diharapkan mampu menjadi tambahan referensi baru dan pembuktian di bidang ilmu manajemen pemasaran terkait brand equity dan hasil penelitian ini dapat digunakan sebagai bahan pertimbangan dan masukan bagi pihak manajemen PT. Mayora Indah Tbk dan PT. Sinar Sosro saat merumuskan kebijakan pemasaran dalam mempertahankan Brand equity merek produk tersebut.

\section{METODE PENELITIAN}

Penelitian ini merupakan jenis penelitian kuantitatif yang berbentuk deskriptif, yang dimana penelitian ini bertujuan untuk mencari tahu mengenai elemen brand equity pada produk minuman teh dalam kemasan merek Teh Botol Sosro dan merek Teh Pucuk Harum. Penelitian ini dilakukan di Kota Denpasar yang mencakup daerah Denpasar Utara, Denpasar Timur, Denpasar Selatan dan Denpasar Barat. Pemilihan Kota Denpasar adalah karena melihat komposisi dari masyarakatnya yang heterogen, berasal dari berbagai daerah lain di Provinsi Bali, serta merupakan ibukota Provinsi Bali. Objek penelitian ini adalah perbedaan 
elemen brand equity pada produk minuman teh dalam kemasan merek Teh Botol Sosro dan merek Teh Pucuk Harum di Kota Denpasar. Subjek dalam penelitian ini adalah konsumen Kota Denpasar yang sudah pernah mengkonsumsi kedua produk minuman Teh Botol Sosro dan Teh Pucuk Harum.

Populasi dalam penelitian ini adalah seluruh masyarakat di Kota Denpasar yang sudah pernah mengkonsumsi produk minuman teh dalam kemasan merek Teh Botol Sosro atau Teh Pucuk Harum, sehingga jumlah populasi dalam penelitian ini tidak terbatas atau infinity karena tidak ada data yang menunjukkan jumlah populasi yang pernah mengkonsumsi kedua produk tersebut. Sedangkan penelitian ini sampel yang digunakan adalah masyarakat Kota Denpasar yang sudah pernah mengkonsumsi Teh Botol Sosro atau Teh Pucuk Harum.

Metode penentuan sampel yang digunakan dalam penelitian ini adalah teknik non probability sampling, yaitu teknik pengambilan sampel yang tidak memberi peluang atau kesempatan yang sama bagi setiap unsur atau anggota populasi untuk dipilih menjadi sampel, dan biasanya teknik ini digunakan pada populasi yang tidak diketahui jumlah pastinya. Teknik non probability sampling yang dipilih adalah Purposive Sampling.

Metode pengumpulan data dalam penelitian ini dilakukan dengan mengajukan daftar pertanyaan yang ditulis dalam satu daftar kepada responden. Kuesioner terdiri dari pertanyaan tertutup dan pertanyaan terbuka. Pertanyaan terbuka meliputi identitas responden dan brand awareness untuk mendeskripsikan kesadaran konsumen. Pertanyaan tertutup adalah pertanyaan yang alternatif jawabannya telah disediakan, dalam penelitian ini variabel brand association, 
perceived quality dan brand loyalty menggunakan pertanyaan tertutup. Untuk variabel brand association akan diukur dengan menggunakan skala Guttman. Penelitian dengan skala Guttman dilakukan bila ingin mendapatkan jawaban yang tegas terhadap suatu permasalahan, skala ini memberikan jawaban pasti terhadap asosiasi apa saja yang terkandung di dalam kedua produk. Untuk variabel, perceived quality dan brand loyalty akan diukur dengan menggunakan skala Likert dengan skala 1 sampai 5. Skala ini mengukur sikap, pendapat, dan persepsi seseorang atas sebuah fenomena (Sugiyono, 2014:131)

\section{HASIL DAN PEMBAHASAN}

Tabel 3

Hasil Uji Validitas Brand Association

\begin{tabular}{|c|c|c|c|}
\hline No & Indikator & Koefisien Korelasi & Keterangan \\
\hline 1 & $\begin{array}{l}\text { Produk tersebut memiliki cita rasa yang } \\
\text { tinggi. }\end{array}$ & 0,795 & Valid \\
\hline 2 & $\begin{array}{l}\text { Produk tersebut memiliki merek terkenal. } \\
\text { Produk tersebut memiliki volume isi produk }\end{array}$ & 0,795 & Valid \\
\hline 3 & yang banyak. & 0,677 & Valid \\
\hline 4 & $\begin{array}{l}\text { Produk tersebut memiliki ciri khas tersendiri. } \\
\text { Produk tersebut memiliki harga yang }\end{array}$ & 0,742 & Valid \\
\hline 5 & terjangkau. & 0,894 & Valid \\
\hline
\end{tabular}

Sumber: Data primer diolah, 2017

Tabel 4

Hasil Uji Validitas Perceived Quality

\begin{tabular}{clcc}
\hline & \multicolumn{1}{c}{ Indikator } & $\begin{array}{c}\text { Koefisien } \\
\text { Korelasi }\end{array}$ & Keterangan \\
\hline & & & \\
2 & Produk tersebut memiliki rasa yang enak saat & 0,927 & Valid \\
3 & Pikonsumsi. & 0,774 & Valid \\
3 & Produk tersebut memiliki tampilan menarik. & 0,904 & Valid \\
4 & Produk tersebut memiliki kualitas yang baik. & 0,859 & Valid \\
5 & Produk tersebut memiliki karakteristik rasa. & 0,738 & Valid \\
6 & Produk tersebut mudah di dapat oleh konsumen. & 0,877 & Valid \\
\hline
\end{tabular}


Tabel 5

Hasil Uji Validitas Brand Loyalty

\begin{tabular}{clcc}
\hline No & \multicolumn{1}{c}{ Indikator } & Koefisien Korelasi & Keterangan \\
\hline 1 & Pembeli yang komit & 0,876 & Valid \\
2 & Pembeli yang menyukai merek & 0,868 & Valid \\
3 & Pembeli yang puas dengan merek & 0,921 & Valid \\
4 & Pembeli yang bersifat kebiasaan & 0,912 & Valid \\
5 & Pembeli yang berpindah-pindah & 0,844 & Valid \\
\hline
\end{tabular}

Sumber: Data primer diolah, 2017

Berdasarkan hasil yang ditunjukkan pada Tabel 3,4,5 dapat dilihat bahwa nilai koefisien korelasi dari masing-masing konstruk menunjukkan nilai yang lebih besar dari 0,3 maka dapat dinyatakan bahwa seluruh konstruk dari masingmasing variabel telah memenuhi syarat validitas data.

Tabel 6

Hasil Uji Reliabilitas

\begin{tabular}{clcc}
\hline No & \multicolumn{1}{c}{ Variabel } & Cronbach Alpha & Keterangan \\
\hline 1 & Brand Association & 0,825 & Reliabel \\
2 & Perceived Quality & 0,920 & Reliabel \\
3 & Brand Loyalty & 0,927 & Reliabel \\
\hline
\end{tabular}

Sumber: Data primer diolah, 2017

Tabel 6 menunjukkan bahwa seluruh variabel memiliki nilai Cronbachalpha yang lebih besar dari 0,7 . Sehingga, dapat dinyatakan seluruh variabel yang digunakan dalam penelitian ini memenuhi syarat konsistensi dan keandalan data.

\section{Tabel 7}

Hasil Analisis Brand Awarness

\begin{tabular}{clccc}
\hline \multirow{2}{*}{ No } & \multicolumn{1}{c}{ Merek Teh } & Indikator & Jumlah (orang) & Persentase \\
\hline \multirow{2}{*}{1} & Teh Botol Sosro & Top of Mind & 62 & 62 \\
& Teh Pucuk Harum & & 27 & 27 \\
\multirow{2}{*}{2} & Teh Botol Sosro & Brand Recall & 30 & 30 \\
& Teh Pucuk Harum & & 54 & 54 \\
\multirow{2}{*}{3} & Teh Botol Sosro & Brand Recognition & 8 & 8 \\
\multirow{2}{*}{4} & Teh Pucuk Harum & & 19 & 19 \\
& Teh Botol Sosro & \multirow{2}{*}{ Brand Unware } & - & - \\
\hline \multirow{2}{*}{ Sumber } & Teh Pucuk Harum & & - & -
\end{tabular}


Dari 100 responden yang dilibatkan dalam penelitian ini, untuk indikator Top of Mind 62\%menyebutkan Teh Botol Sosro sebagai merek yang pertama kali diingat responden, sementara 27\% paling mengingat merek Teh Pucuk Harum, dan sisanya $11 \%$ menyebutkan merek lain diluar merek-merek yang diteliti. Hasil penelitian untuk indikator Top of Mind menunjukkan bahwa merek Teh Botol Sosropaling diingat oleh sebagian besar responden. Hal ini dikarenakan Teh Botol Sosro adalah merek produk yang telah lama berada di pasaran teh dalam kemasan. Selain itu Teh Botol Sosro memiliki jargon yang familiar dibenak konsumen. Merek Teh Pucuk Harum kurang diingat karena produk Teh Pucuk Harum belum cukup lama berada di pasaran teh dalam kemasan dan adanya banyak pesaing dari minuman teh dalam kemasan membuat Teh Pucuk Harum memiliki persentase lebih kecil dibandingkan Teh Botol Sosro.

Hasil penelitian Brand recall menunjukkan merek Teh Pucuk Harum mendapatkan persentase tertinggi dengan total $54 \%$ atau 54 orang. Sedangkan Teh Botol Sosro sebesar $30 \%$ atau 30 orang. Merek Teh Botol Sosro memiliki persentase lebih kecil dibandingkan Teh Pucuk Harum karena sebagian besar responden sudah menyebutkan merek tersebut sebagai merek yang pertama kali diingat. Sehingga dari perbandingan tersebut merek teh dalam kemasan yang harus memperbaiki kinerjanya agar menjadi lebih baik sehingga dapat lebih diingat konsumen adalah Teh Pucuk Harum. Untuk merek Teh Botol Sosro sudah baik karena jumlah responden pada top of mind lebih banyak dibanding jumlah responden pada brand recall. 
Hasil jawaban pada kuesioner yang menunjukkan brand recognition adalah pertanyaan nomor 3 dan 4 pada poin b yaitu 'ya, tapi saya lupa mencantumkan pada jawaban diatas'. Hasil penelitian brand recognition dapat dilihat pada Tabel 4.6. Dari tabel diatas dapat dilihat bahwa jumlah orang yang harus diingatkan dengan merek Teh Botol Sosro sebanyak 8 orang atau $8 \%$ dari 100 responden dan untuk merek Teh Pucuk Harum sebanyak19 orang atau 19\%. Hal ini menunjukkan bahwa merek Teh Pucuk Harum perlu diberikan bantuan lebih banyak untuk mengingat merek dibandingkan Teh Botol Sosro. Walaupun telah melakukan promosi, beberapa responden masih ada yang memerlukan bantuan untuk mengingat kedua produk tersebut, itu dikarenakan produk teh dalam kemasan terdapat berbagai jenis produk lainnya, dengan varian rasa dan bentuk yang berbeda.

Setelah semua indikator dari kesadaran merek dihitung, maka dapat disusun dalam suatu kesatuan berbentuk piramida kesadaran merek pada Gambar 1

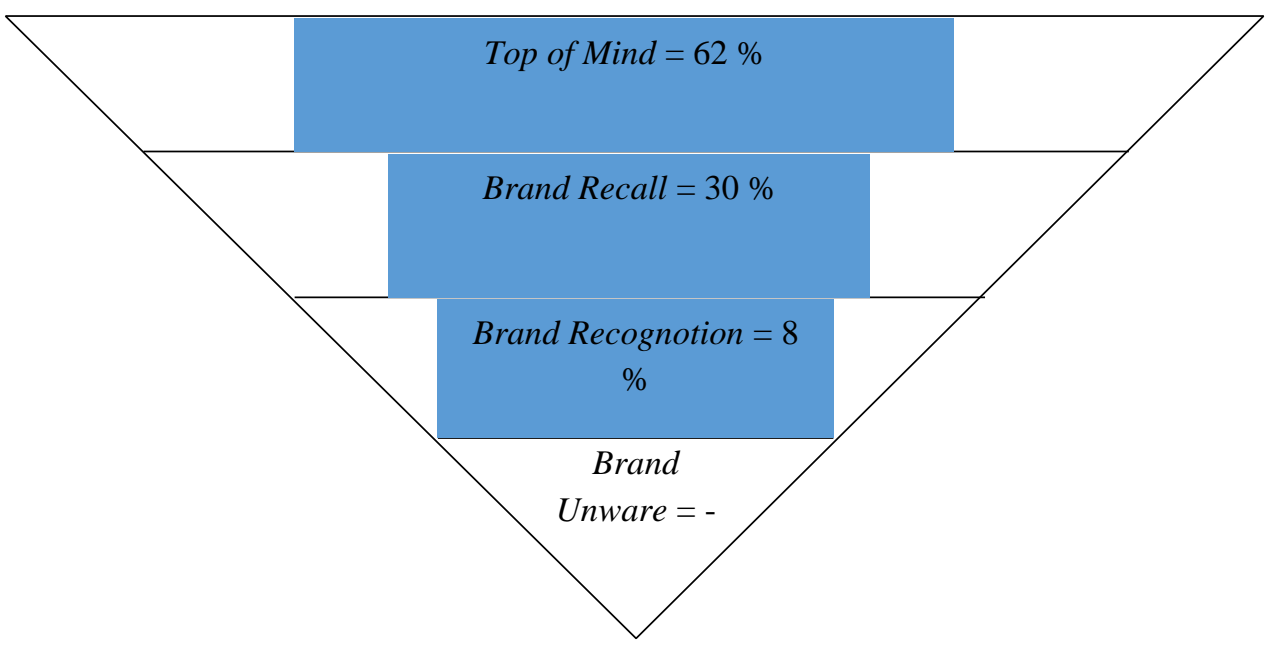

\section{Gambar 1 Piramida Kesadaran Merek Teh Botol Sosro}

Sumber: Tabel 7 Hasil Analisis Brand Awarness 
Pada Gambar 1 menunjukkan bahwa kondisi merek Teh Botol Sosro sudah baik karena nilai dari masing-masing indikator semakin keatas semakin tinggi. Pada tingkat kesadaran merek yang paling diingat atau Top of Mind memiliki nilai tertinggi yaitu $62 \%$ pada tingkat brand recall yaitu sebesar $30 \%$ Pada tingkatan brand recognition yaitu sebesar $8 \%$ Pada tingkatan brand unaware merupakan tingkatan paling rendah dalam pengukuran kesadaran merek yaitu sebesar 0 responden, itu berarti tidak ada konsumen yang tidak mengetahui merek Teh Botol Sosro. Tingkat Top of Mind Teh Botol Sosro memiliki nilai kesadaran paling tinggi dibanding indikator lainnya, manajemen Teh Botol Sosro harus tetap menjaga tingkat kesadaran konsumen agar produk Teh Botol Sosro tetap dapat disukai oleh konsumen.

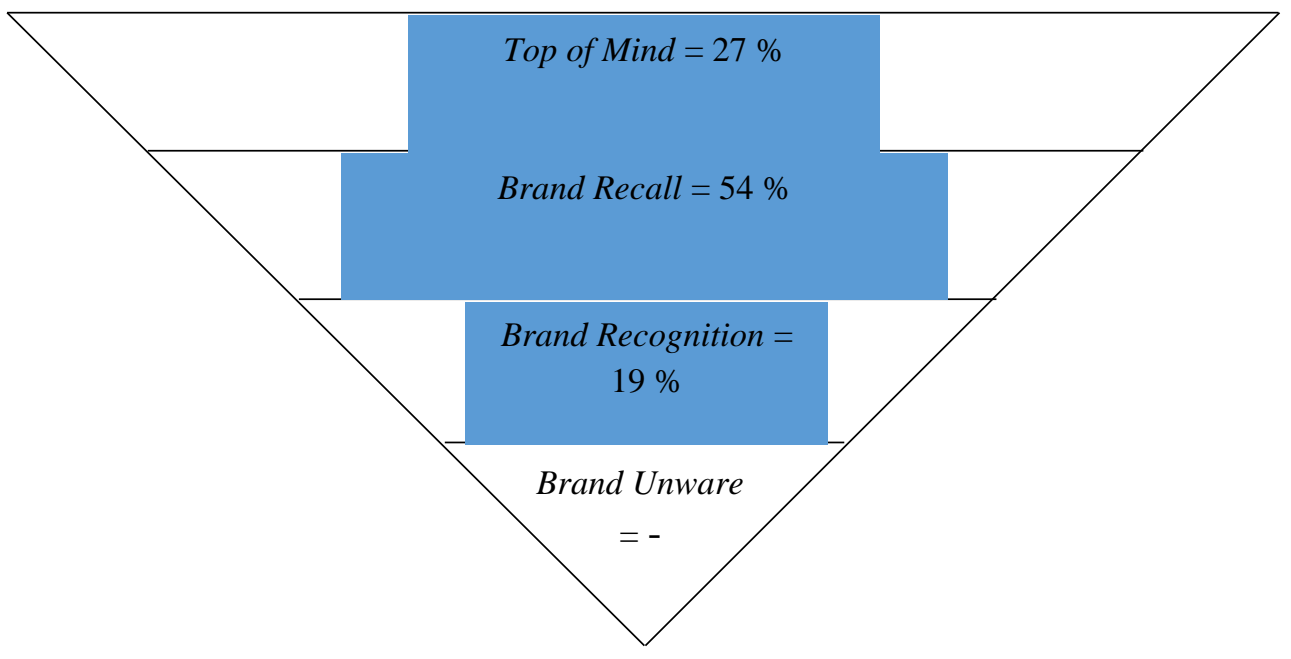

\section{Gambar 2 Piramida Kesadaran Merek Teh Pucuk Harum}

Sumber: Tabel 7 Hasil Analisis Brand Awarness

Pada Gambar 2 menunjukkan bahwa kondisi merek Teh Pucuk Harumcukup baik karena nilai dari masing-masing indikator semakin keatas semakin tinggi, namun hal yang perlu diperhatikan yaitu pada tingkat indikator Top of Mind, pada tingkat Top of Mind memiliki nilai tertinggi yaitu 27\% pada tingkat brand recall 
mencerminkan merek apa yang diingat setelah menyebutkan merek pertama kali disebut yaitu sebesar 54\% Pada tingkatan brand recognition dimana kesadarannya akan merek muncul ketika dengan diberikan bantuan pertanyaan untuk mengingat suatu merek yaitu sebesar 19\% Pada tingkatan brand unaware merupakan tingkatan paling rendah dalam pengukuran kesadaran merek yaitu sebesar 0 responden, itu berarti tidak ada konsumen yang tidak mengetahui merek Teh Pucuk Harum. Tingkat Brand Recall mencerminkan merek apa yang diingat setelah menyebutkan merek pertama kali disebut Teh Pucuk Harum lebih tinggi dibandingkan tingkat Top of Mind Teh Pucuk Harum hal tersebut perlu diperhatikan karena produk Teh Pucuk Harum masih sedikit diingat oleh responden pertama kali. Manajemen Teh Pucuk Harum perlu memperhatikan kesadaran konsumen akan merek, mengingat pesaing produk tersebut cukup banyak, agar nantinya produk Teh Pucuk Harum tetap dapat bersaing dengan merek produk yang lainnya.

Hasil yang diperoleh dari 100 responden pengkonsumsi merek Teh Botol Sosro dan Teh Pucuk Harum yang menjawab 'ya' pada setiap pertanyaan asosiasi merek ditunjukkan pada Tabel 8 dan Tabel 9.

\section{Tabel 8}

\section{Penilaian Responden terhadap The Botol Sosro}

\begin{tabular}{cccc}
\hline No & Asosiasi & Jawaban 'Ya' & Persentase \\
\hline 1 & Produk tersebut memiliki cita rasa yang tinggi. & 61 & 61 \\
2 & Produk tersebut memiliki merek terkenal. & 61 & 61 \\
3 & Produk tersebut memiliki volume isi produk yang & 40 & 40 \\
4 & banyak. & 54 & 54 \\
5 & Produk tersebut memiliki ciri khas tersendiri. & 57 & 57 \\
\hline Sumber: Data primer diolah, 2017
\end{tabular}




\section{Tabel 9}

Penilaian Responden terhadap Teh Pucuk Harum

\begin{tabular}{clcc}
\hline No & \multicolumn{1}{c}{ Asosiasi } & Jawaban 'Ya' & Persentase \\
\hline 1 & Produk tersebut memiliki cita rasa yang tinggi. & 56 & 56 \\
2 & Produk tersebut memiliki merek terkenal. & 55 & 55 \\
3 & $\begin{array}{l}\text { Produk tersebut memiliki volume isi produk yang } \\
\text { banyak. }\end{array}$ & 56 & 56 \\
5 & Produk tersebut memiliki ciri khas tersendiri. & 37 & 37 \\
5 & Produk tersebut memiliki harga yang terjangkau. & 57 & 57 \\
\hline
\end{tabular}

Tabel 10

Nilai Performance-Importance Merek Teh Botol Sosro

\begin{tabular}{clccc}
\hline No & \multicolumn{2}{c}{ Teh Botol Sosro } & Performance & Importance \\
\hline & Produk tersebut memiliki rasa yang enak saat & & \\
1 & dikonsumsi. & & 4,71 & 4,71 \\
2 & Produk tersebut memiliki tampilan menarik. & 3,35 & 4,82 \\
3 & Produk tersebut memiliki kualitas yang baik. & 4,75 & 4,75 \\
4 & Produk tersebut aman bagi kesehatan. & 4,06 & 3,69 \\
5 & Produk tersebut memiliki karakteristik rasa. & 2,37 & 4,68 \\
6 & Produk tersebut mudah di dapat oleh konsumen. & 4,68 & 4,35 \\
\hline \multicolumn{2}{r}{ Rata-rata } \\
\hline
\end{tabular}

Sumber: Data primer diolah, 2017

Selanjutnya tingkat performance dan importance merek Teh Botol Sosro dapat digambarkan dalam bentuk diagram cartesius berikut ini. Tingkat performance digambarkan pada sumbu horizontal $(\mathrm{X})$ dan tingkat importance digambarkan pada sumbu vertikal (Y). Nilai ditetapkan dari hasil pilihan responden mengenai performance (kinerja dari perusahaan) dan importance (harapan konsumen yang terkait dengan atribut yang diteliti) digunakan diagram cartesius yang terbagi atas empat kuadran.

Setiap kuadran menggambarkan terjadinya suatu kondisi yang berbeda dengan kuadran lainnya. Kuadran pertama bercirikan, performance rendah tetapi importance tinggi, yang disebut underact. Kuadran kedua bercirikan performance tinggi dan importance yang tinggi pula, sehingga keadaan ini harus terus dipelihara/maintain. Kuadran ketiga menggambarkan tingkat performance rendah 
dan importance yang juga rendah, sehingga disebut daerah low priority. Kuadran yang keempat, tingkat performance tinggi tetapi importance rendah, yang disebut overact. Cara mencari nilainya adalah dengan menggunakan perhitungan rata-rata yang hasilnya akan dipetakan dalam bentuk diagram cartesius, berupa grafik importance performance.

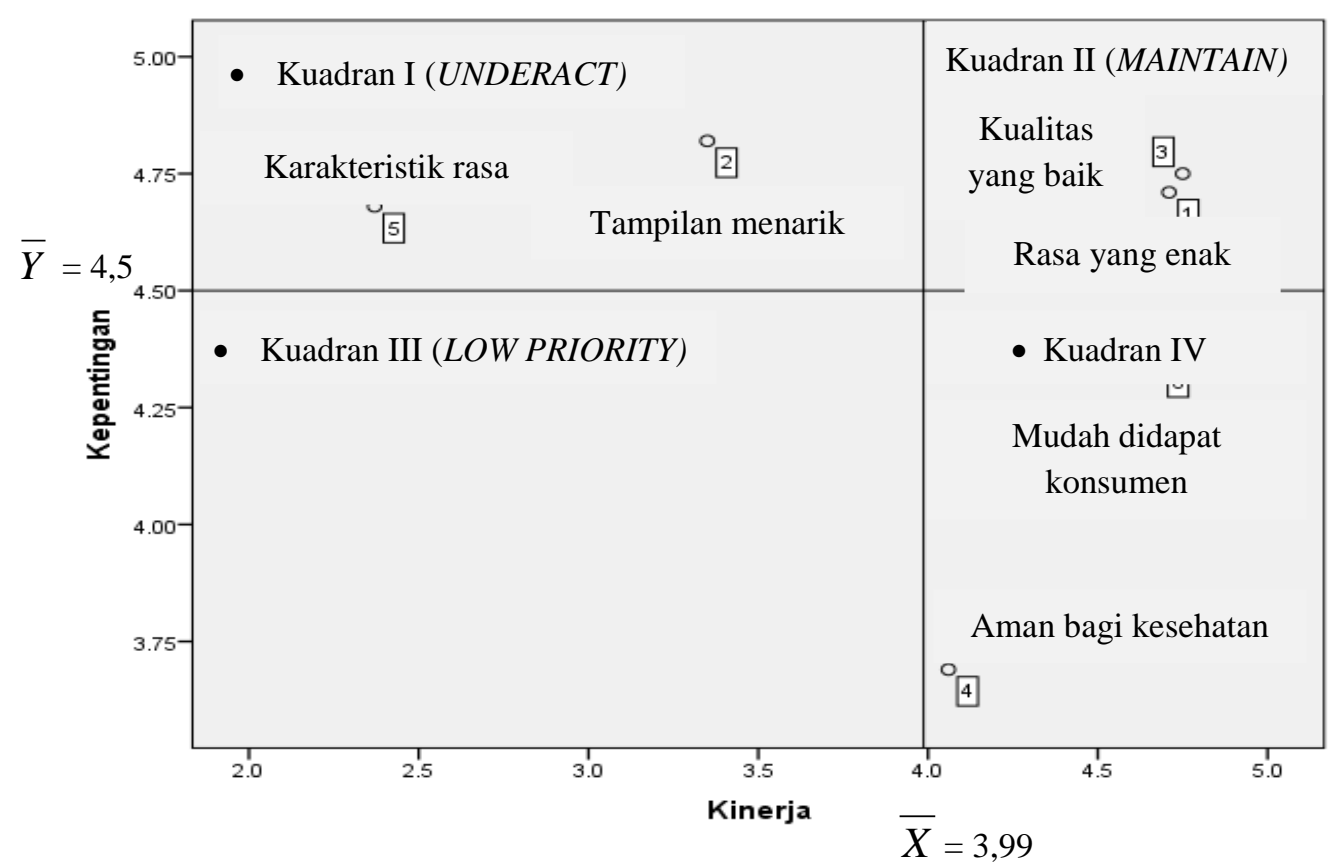

Gambar 3 Diagram Performance-Importance Merek Teh Botol Sosro

Sumber: Tabel 10 Nilai Performance-Importance Merek Teh Botol Sosro

Pada Gambar 3 dapat dijelaskan bahwa pada kuadran pertama (underact), merek Teh Botol Sosro menurut persepsi konsumen terhadap atribut memiliki tampilan menarik (2) dan memiliki karakteristik rasa (5) menunjukkan bahwa kinerja atribut lebih rendah dari kepentingan konsumen, oleh karena itu atribut pada kuadran ini merupakan atribut yang diprioritaskan untuk meningkatkan kepuasan pelanggan. 
Pada kuadran kedua (maintain) yaitu atribut memiliki rasa enak (1) dan kualitas yang baik (3) pada merek Teh Botol Sosro harus tetap dijaga dan dipertahankan, karena menurut persepsi konsumen atribut-atribut tersebut sudah baik. Untuk kuadran keempat (overact), atribut aman bagi kesehatan (4) dan mudah didapat (6), jika dilihat dari kepentingan konsumen berada pada tingkat kepentingan yang rendah, tetapi dari kinerja merek yang dilakukan, konsumen menilai bahwa kinerja atribut tersebut berada pada tingkat yang paling tinggi sehingga Teh Botol Sosro tidak perlu melakukan perbaikan. Jadi persepsi kualitas merek Teh Botol Sosro yang baik menurut persepsi konsumen yaitu rasa yang enak dan kualitas yang baik.

Tabel 11

Nilai Performance-Importance Merek Teh Pucuk Harum

\begin{tabular}{|c|c|c|c|}
\hline No & The Pucuk Harum & Performance & Importance \\
\hline 1 & $\begin{array}{l}\text { Produk tersebut memiliki rasa yang enak saat } \\
\text { dikonsumsi. }\end{array}$ & 4,84 & 4,84 \\
\hline 2 & Produk tersebut memiliki tampilan menarik. & 4,07 & 4,93 \\
\hline 3 & Produk tersebut memiliki kualitas yang baik. & 4,9 & 4,56 \\
\hline 4 & Produk tersebut aman bagi kesehatan. & 4,75 & 4,69 \\
\hline 5 & Produk tersebut memiliki karakteristik rasa. & 2,75 & 4,79 \\
\hline \multirow[t]{2}{*}{6} & Produk tersebut mudah di dapat oleh konsumen. & 4,93 & 4,83 \\
\hline & Rata-rata & 4,37 & 4,77 \\
\hline
\end{tabular}

Selanjutnya tingkat performance dan importance merek Teh Pucuk Harum dapat digambarkan dalam bentuk diagram cartesius berikut ini. Tingkat performance digambarkan pada sumbu horizontal (X) dan tingkat importance digambarkan pada sumbu vertikal (Y). Nilai ditetapkan dari hasil pilihan responden mengenai performance (kinerja dari perusahaan) dan importance (harapan konsumen yang terkait dengan atribut yang diteliti) digunakan diagram cartesius yang terbagi atas empat kuadran. 


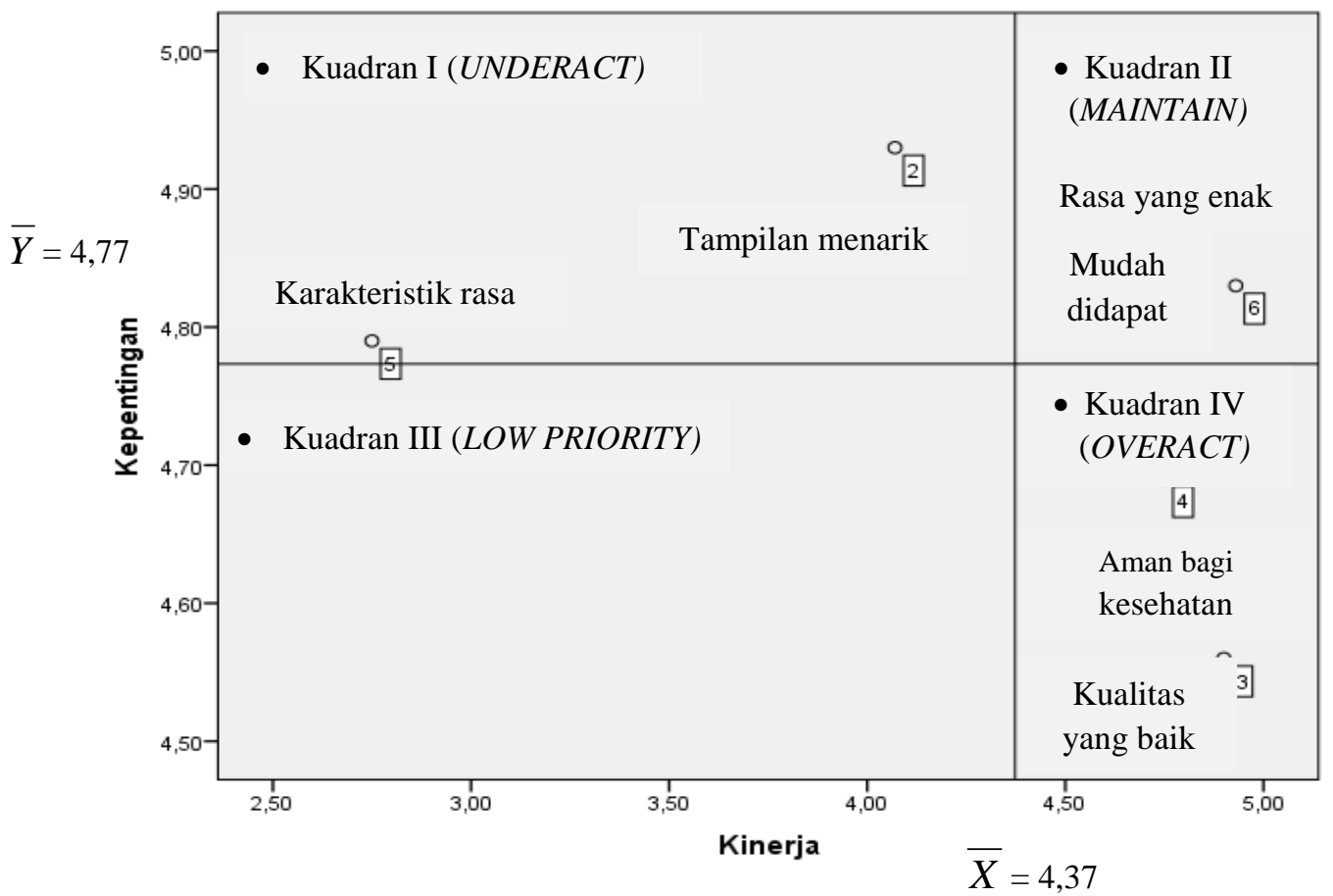

Gambar 4 Diagram Performance-Importance Merek Teh Pucuk Harum Sumber: Tabel 11 Nilai Performance-Importance Merek Teh Pucuk Harum

Pada Gambar 4 dapat dijelaskan bahwa pada kuadran pertama (underact), merek Teh Pucuk Harum menurut persepsi konsumen terhadap atribut memiliki tampilan menarik (2) dan memiliki karakteristik rasa (5) menunjukkan bahwa kinerja atribut lebih rendah dari kepentingan konsumen.

Pada kuadran kedua (maintain) yaitu atribut memiliki rasa enak (1) dan mudah didapatkan (6) pada merek Teh Pucuk Harum harus tetap dijaga dan dipertahankan, karena menurut persepsi konsumen atribut-atribut tersebut sudah baik.

Untuk kuadran keempat (overact), atribut memiliki kualitas baik (3) dan aman bagi kesehatan (4), jika dilihat dari kepentingan konsumen berada pada tingkat kepentingan yang rendah, tetapi dari kinerja merek yang dilakukan, konsumen menilai bahwa kinerja atribut tersebut berada pada tingkat yang paling 
tinggi sehingga Teh Pucuk Harum tidak perlu melakukan perbaikan. Jadi persepsi kualitas merek Teh Pucuk Harum yang baik menurut persepsi konsumen yaitu rasa yang enak dan mudah didapat.

Tabel 12

Penilaian Responden terhadap Indikator Switcher

\begin{tabular}{cccccc}
\hline \multirow{2}{*}{ No } & Indikator & Jawaban & Bobot & $\begin{array}{c}\text { Teh Botol } \\
\text { Sosro }\end{array}$ & $\begin{array}{c}\text { Teh Pucuk } \\
\text { Harum }\end{array}$ \\
\hline \multirow{4}{*}{1} & Selalu & 1 & 3 & 2 \\
& & Sering & 2 & 23 & 28 \\
& & Kadang- & & & 41 \\
& & Kadang & 3 & 40 & 22 \\
& Jarang & 4 & 27 & 7 \\
\hline & Tidak Pernah & 5 & 7 & 100 \\
\hline & Total & & 100 & 3,04 \\
\hline
\end{tabular}

Sumber: Data primer diolah, 2017

Berdasarkan hasil perhitungan switcher (pembeli yang berpindah-pindah) dimana konsumen tidak memiliki rasa loyal terhadap suatu merek. diperoleh bahwa rata-rata responden merek Teh Botol Sosro kadang-kadang ada yang berpindah merek. Hal ini dapat ditunjukkan dengan nilai rataan sebesar 3,12. Responden yang sensitif terhadap perubahan atribut produkberjumlah 26 responden. Rata-rata responden merek Teh Pucuk Harum kadang-kadang ada yang berpindah merek. Hal ini dapat ditunjukkan dengan nilai rataan sebesar 3,04. Responden yang sensitif terhadap perubahan atribut produk berjumlah 30 responden. Dari hasil ini dapat diketahui Teh Pucuk Harum merupakan merek yang memiliki konsumen paling sensitif terhadap perubahan atribut dibandingkan Teh Botol Sosro, maka dari itu Teh Pucuk Harum harus mampu menjaga kestabilan harga dari produknya tersebut agar konsumen produk Teh Pucuk Harum tetap dapat menyukai produk tersebut. 
Tabel 13

Penilaian Responden terhadap Indikator Habitual Buyer

\begin{tabular}{|c|c|c|c|c|c|}
\hline \multirow{2}{*}{ No } & \multirow{2}{*}{ Indikator } & \multirow{2}{*}{ Jawaban } & \multirow{2}{*}{ Bobot } & \multicolumn{2}{|c|}{ Frekuensi } \\
\hline & & & & Teh Botol Sosro & Teh Pucuk Harum \\
\hline \multirow{5}{*}{1} & \multirow{5}{*}{$\begin{array}{l}\text { Habitual } \\
\text { Buyer }\end{array}$} & Sangat Tidak Setuju & 1 & 6 & 6 \\
\hline & & Tidak Setuju & 2 & 27 & 30 \\
\hline & & Ragu-Ragu & 3 & 20 & 22 \\
\hline & & Setuju & 4 & 39 & 37 \\
\hline & & Sangat Setuju & 5 & 8 & 5 \\
\hline & & Total & & 100 & 100 \\
\hline & & Rata-rata & & 3,16 & 3,05 \\
\hline
\end{tabular}

Sumber: Data primer diolah, 2017

Habitual buyer (pembeli yang bersifat kebiasaan) alasan mendasar membeli suatu produk adalah berdasarkan kebiasaan yang dilakukan selama ini. Berdasarkan hasil perhitungan habitual buyer yang ditunjukkan pada Tabel 13 diperoleh bahwa rata-rata responden merek Teh Botol Sosro merasa ragu-ragu bahwa keputusan pembelian Teh Botol Sosro adalah karena kebiasaan, ini ditunjukkan oleh nilai rataan sebesar 3,16, sedangkan responden yang benar-benar membeli karena kebiasaan berjumlah 47 orang. Responden merek Teh Pucuk Harum merasa ragu-ragu bahwa keputusan pembelian Teh Pucuk Harum adalah karena kebiasaan, ini ditunjukkan oleh nilai rataan sebesar 3,05, sedangkan responden yang benar-benar membeli karena kebiasaan berjumlah 42 orang.

Tabel 14

Penilaian Responden terhadap Indikator Satisfied Buyer

\begin{tabular}{cccccc}
\hline \multirow{2}{*}{ No } & \multirow{2}{*}{ Indikator } & \multirow{2}{*}{ Jawaban } & \multirow{2}{*}{ Bobot } & \multicolumn{3}{c}{ Frekuensi } \\
& & & Teh Botol Sosro & Teh Pucuk Harum \\
\hline \multirow{4}{*}{1} & & Sangat Tidak Puas & 1 & 1 & 2 \\
& Satisfied & Tidak Puas & 2 & 1 & 4 \\
& Buyer & Biasa Saja & 3 & 40 & 51 \\
& & Puas & 4 & 52 & 39 \\
& & Sangat Puas & 5 & 8 & 4 \\
\hline & Total & & 100 & 3,39 \\
\hline
\end{tabular}

Sumber: Data primer diolah, 2017 
Berdasarkan hasil perhitungan satisfied buyer diperoleh bahwa rata-rata responden Teh Botol Sosro merasa puas menggunakan merek tersebut. Hal ini dapat ditunjukkan dari nilai rata-rata jawaban responden sebesar 3,61 sedangkan responden yang meraa puas berjumlah 60 orang. Responden Teh Pucuk Harum merasa biasa saja menggunakan merek tersebut. Hal ini dapat ditunjukkan dari nilai rata-rata jawaban responden sebesar 3,39 sedangkan responden yang meraa puas berjumlah 43 orang.

Tabel 15

Penilaian Responden terhadap Indikator Liking The Brand

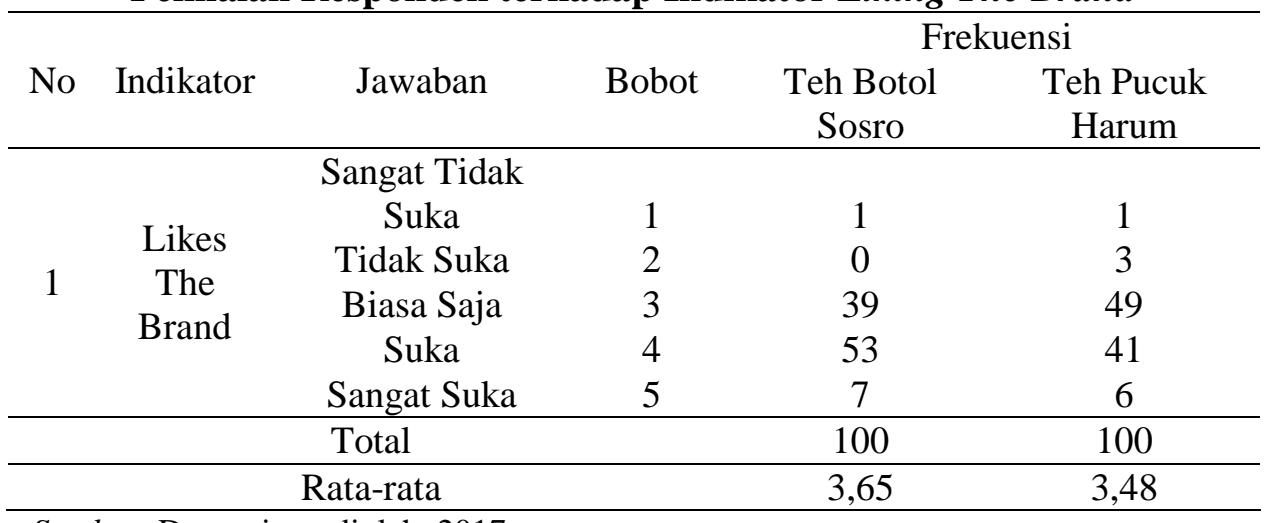

Sumber: Data primer diolah, 2017

Berdasarkan hasil perhitungan liking the brand diperoleh bahwa rata-rata responden merek Teh Botol Sosro setuju bahwa mereka menyukai merek tersebut, hal ini terbukti dari jawaban rata-rata responden sebesar 3,65. Sedangkan jumlah responden yang benar-benar menyukai merek Teh Botol Sosro berjumlah 60 orang. Rata-rata responden merek Teh Pucuk Harum setuju bahwa mereka menyukai merek tersebut, hal ini terbukti dari jawaban rata-rata responden sebesar 3,48. Sedangkan jumlah responden yang benar-benar menyukai merek Teh Pucuk Harum berjumlah 47 orang. 
Tabel 16

Penilaian Responden terhadap Indikator Commited Buyer

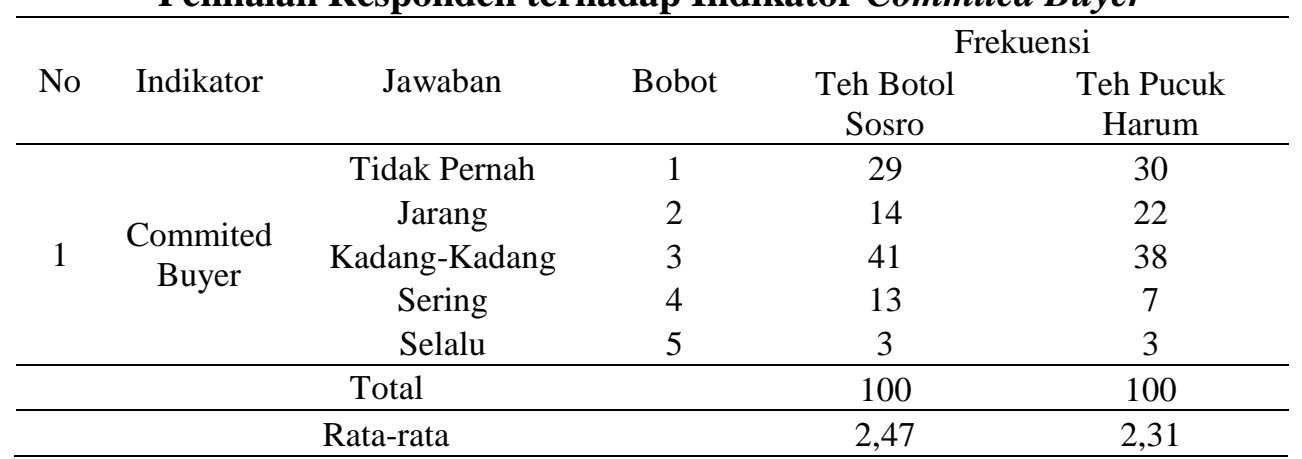

Sumber: Data primer diolah, 2017

Berdasarkan hasil perhitungan commited buyer diperoleh bahwa responden merek Teh Botol Sosro jarang mempromosikan merek tersebut, hal ini terbukti dari jawaban rata-rata responden sebesar 2,47 dan yang termasuk committed buyer sebanyak 16 orang. Rata-rata responden merek Teh Pucuk Harum jarang mempromosikan merek tersebut, hal ini terbukti dari jawaban rata-rata responden sebesar 2,31 dan yang termasuk committed buyer sebanyak 10 orang.

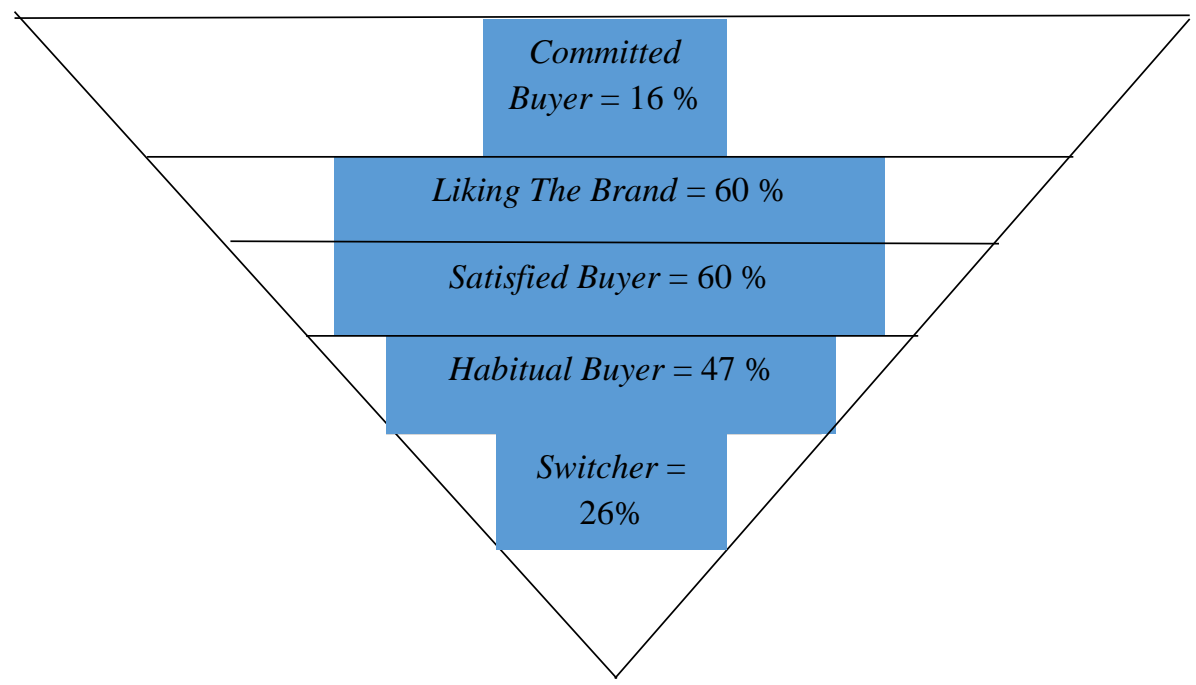

Gambar 5 Piramida Loyalitas Merek Teh Botol Sosro

Sumber: Hasil Analisis Tiap Indikator Brand Loyalty

Pada Gambar 5 menunjukkan bahwa kondisi merek Teh Botol Sosro cukup baik karena bentuk piramida semakin ke atas semakin melebar, tetapi pada level 
commited buyer (pembeli yang komit terhadap suatu merek tertentu) terlihat mengecil dengan jumlah persentase sebesar $16 \%$. Hal ini perlu mendapatkan perhatian dari pihak manajemen Teh Botol Sosro agar jumlah konsumen yang memiliki kesetiaan pada produk tersebut dapat bertambah. Pada tingkatan loyalitas merek, responden yang termasuk switcher sebesar $26 \%$, responden yang merupakan habitual buyer sebesar 47\%, responden yang merupakan satisfied buyer sebesar $60 \%$, dan responden yang merupakan liking the brand sebesar $60 \%$.

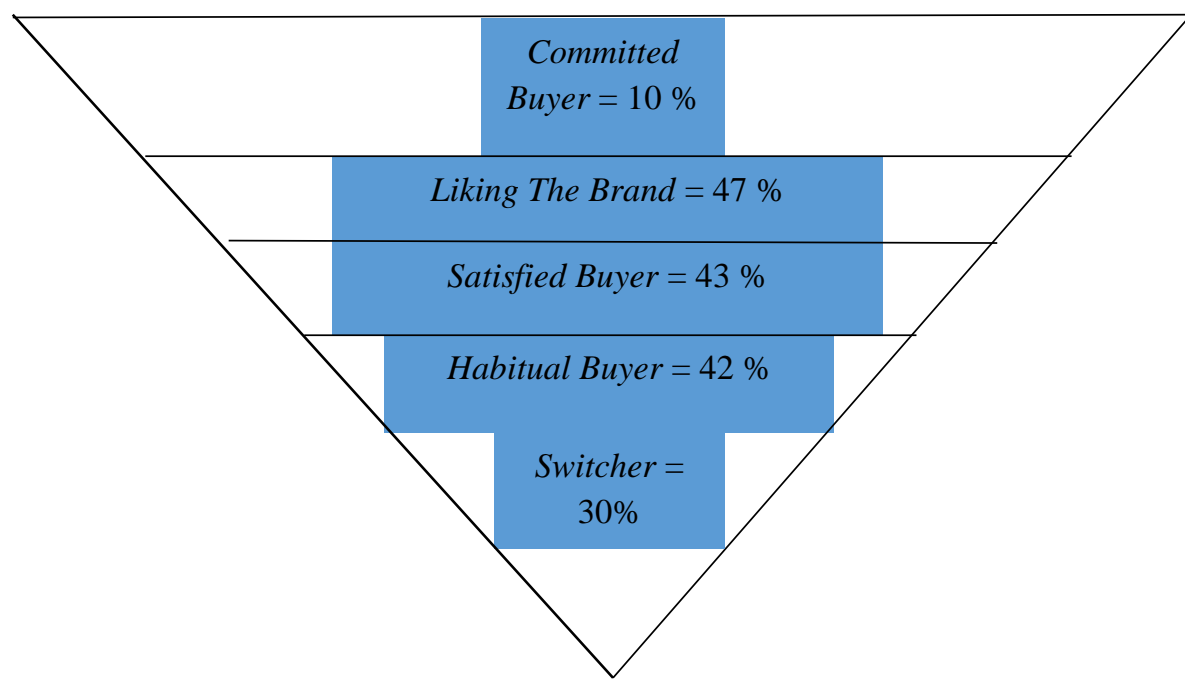

Gambar 6 Piramida Loyalitas Merek Teh Pucuk Harum

Sumber: Hasil Analisis Tiap Indikator Brand Loyalty

Pada Gambar 6 menunjukkan bahwa kondisi merek Teh Pucuk Harum cukup baik karena bentuk piramida semakin ke atas semakin melebar, tetapi pada level commited buyer terlihat mengecil dengan jumlah persentase sebesar $10 \%$. Hal ini perlu mendapatkan perhatian dari pihak manajemen Teh Pucuk Harum. Pada tingkatan loyalitas merek, responden yang termasuk switcher sebesar 30\%, responden yang merupakan habitual buyer sebesar 42\%, responden yang merupakan satisfied buyer sebesar 43\%, dan responden yang merupakan liking the brand sebesar $47 \%$ Tingkat liking the brand merupakan tingkat kesetiaan yang 
paling besar, karena itu manajemen Teh Pucuk Harum harus tetap menjaga hubungan baik dengan konsumen agar jumlah konsumen yang memiliki kesetiaan pada produk tersebut dapat bertambah.

\section{SIMPULAN DAN SARAN}

Simpulan yang dapat diberikan dalam penelitian ini adalah Elemen Brand Awarness untuk produk Teh Botol Sosro memiliki tingkat kesadaran merek yang baik, dimana $62 \%$ responden paling mengingat produk tersebut dan tidak ada responden yang tidak mengetahui produk Teh Botol Sosro. Selanjutnya Elemen Brand Awarness untuk produk Teh Pucuk Harum memiliki tingkat kesadaran merek yang cukup baik yakni sebesar 27\%, namun sebagian besar responden mengingat produk tersebut setelah menyebutkan merek pertama kali disebut yakni sebesar 54\%. Terdapat perbedaan brand equity dari merek Teh Botol Sosro dan Teh Pucuk Harum. Merek Teh Botol Sosro merupakan merek yang memiliki keunggulan dari elemen brand awarenessdimana keunggulan dari produk tersebut terlihat dari indikator top of mind yaitu sebesar 62\% dan Teh Pucuk Harum sebesar $27 \%$,

Peneliti menyarankan kepada peneliti selanjutnya hanya dilakukan dalam kurun waktu kurang dari setahun dan perubahan pola hidup masyarakat pasti akan berubah, sehingga bisa dilakukan penelitian lanjutan seiring berubahnya waktu dan tingkat konsumsi masyarakat dan dikarenakan penelitian ini hanya dilakukan di Kota Denpasar, diharapkan penelitian selanjutnya bisa dilakukan di Provinsi Bali dengan ruang lingkup yang lebih luas. 
Peneliti juga menyarankan kepada pihak manajemen agar produk Teh Botol Sosro harus bisa mempertahankan kesadaran konsumen terhadap produk dan Teh Pucuk Harum harus lebih bisa meningkatkan kesadaran merek konsumen terhadap produknya dengan cara memberikan pesan iklan yang dengan mudah masuk ke benak konsumen.

\section{REFERENSI}

Aaker, David A. 2013. Manajemen Pemasaran Strategis. Edisi 8. Jakarta: Salemba Empat.

Aditya, Kadek Yoga., dan I Made Wardana. 2017. Peran Brand Equity dalam Memediasi Pengaruh Word of Mouth terhadap Niat Beli. E-Journal Manajemen Universitas Udayana, 6(2):830-856.

Alam, Waqar., Saeed, Tahir., dan Malik, Zilakat Khan. 2016. Role of Brand Image on Brand Equity: A Comparative Study of Public and Private Sector Higher Education Institutions of Khyber Pakhtunkhwa. City University Research Journal,6(1):48-60.

Aristyani, Ida Ayu Raras., dan Ni Nyoman Kertiyasa. 2013, Perbandingan Brand Equity Produk Shampoo Merek Sunsilk Dengan Merek Pantene. Jurnal Manajemen dan Kewirausahaan,15(2):179-190.

Armandhani, Herdian., dan I Putu Gde, Sukaadmaja. 2014. Analisis Perbandingan Brand Equity Produk Obat Anti Nyamuk Oles Merek Autan dengan Merek Soffel di Kota Denpasar. E-Journal Manajemen Universitas Udayana, 3(1):149-168.

Arora, Sangeeta., dan Neha. 2016. Determinants of Customer-based Brand Equity: A Study of Public and Private Banks. Sage Journals, 17(4):905-920.

Bagram dan Khan. 2012. Attaining Customer Loyalty! The Role of Costumer Attitude and Costumer Behavior. International Review of Management and Business Research, 1(1):1-8.

Bakhtiar, Arfan., dan Jayanto, Dwi. 2015. Analisis Elemen-Elemen Brand Equity pada Produk Kartu Seluler Prabayar di Kalangan Mahasiswa S1 Universitas Diponegoro. Journal Teknik Industry, 10(3):155-162

Chen, Hui-Chu., Trans World University, Green, Robert D., Lynn University, 2012, Brand Equity, marketing strategy, and consumer income: A 
hypermarket study. International Business \& Economics Research Journal,11(2):1-18.

Chen, Tser-Yieth., Yeh, Tsai-Lien., and Jheng Wun-Sin. 2013. Factor influencing brand association. African Journal of Business Management,7(19):19141926.

Darmawan, Hudayah Syarifah., Asnawati 2016. Perbandingan Ekuitas Merek Indomie dan Mie Sedaap. Jurnal Manajemen, 8(2):113-135.

Dermawan, Harritz. 2008. Analisis Brand Equity Beberapa Merek Wafer pada Remaja Tingkat Sekolah Menengah Atas. Skripsi. Universitas Institut Pertanian Bogor.

Durianto, Darmadi., dan Sugiarto, Tony Sitinjak. 2004, Strategi Menaklukan Pasar Melalui Riset Ekuitas dan Perilaku Merek. Jakarta: PT. Gramedia Pustaka Utama.

Erfan, Severi. 2012, The Mediating Effects of Brand Association, Brand Loyalty, Brand Image and Perceived Quality on Brand Equity. Asian Social Science, 9(3):125-137.

Ferdinand, Augusty. 2002. Structural Equation Modeling dalam Penelitian Manajemen. Semarang: BP UNDIP.

Garlina, Yossy Hanna. 2014. Comparison of Skin Moisturizer: Consumer-Based Brand equity(Cbbe) Factors in Clusters Based On Consumer Ethnocentrism. Journal The Winners, 15(2):115-122.

Gumilang., Galih Ratri., Hariyadi, Sugeng., dan Prihastuty, Rahmawati. 2013. Perbedaan Brand Equity pada Handphone Blackberry dan Samsung Android (Studi Pada Konsumen Pengguna Handphone Ganda Blackberry dan Samsung Android di Semarang). Journal of Social and Industrial Psychology, 2(1):28-31.

Hamka. 2012. Analisis Ekuitas Merek Kecap di Kota Ternate. Journal Agribisnis Kepulauan, 1(1):29-41.

Huang, Chun-Chen., Yen, Szu-Wei., and Liu, Cheng-Yi. 2014. The Relationship Among Brand Equity, Customer satisfaction, and Brand Resonance to Repurchase Intention of Cultural and Creative Industries in Taiwan. The International Journal of Oranizational Innovation, 6(3):106-121.

Hung, Jui-Ying., Lin, Feng Li., Yang, Wen-Goang. 2012. Comparative Study on Diferent Viewpoints of Luxury Brand Equity Based on the Luxury Resort 
Hotel in Taiwan and Macao. African Journal of Business Management, 6(32):9335-9342.

Jung, Jae Hee., and Sung, Eun-Young. 2008. Consumer-based brand equity comparrisons among Americans and South Koreans in the USA and South Koreans in Korea. Journal of Fashion Marketing and Management, 12(1):24-35

Listiana, Erna. 2015. Studi Komparatif Ekuitas Merek Produk Buatan Malaysia dan Indonesia. Journal Ekonomi Bisnis dan Kewirausahaan, 4(2):228-252

Muhammad., dan Abdurachman, Edi. 2009. Analisis Elemen-Elemen Ekuitas Merek (Brand Equity) dari Produk Kartu Telepon CDMA. Journal of Business Strategy and Execution, 1(2):347-365

Nor, Hazlin., Abidin, Nurazariah., dan Borhan, Hafizzah Bashira. 2016. Perceived Quality and Emotional Value That Influence Costumer's Purchase Intention Towards American and Local Product. Procedia Economic and Finance, 3(5):639-643

Nugroho, S. A. 2013. Pengaruh Daya Tarik Iklan dan Kekuatan Celebrity Endorser terhadap Brand Awarness dan Dampaknya terhadap Brand Attitude Handphone Nokia (Studi Kasus pada Mahasiswa dan Mahasiswi Fakultas Ekonomika dan Bisnis Universitas Diponegoro Semarang). Diponegoro Journal of Management, 2(3):1-11.

Omer, Kursad Tufekci. 2014, Audience-Based Brand Equity: A Research on "Women's Tennis Association Championships Istanbul 2013. International Business Research,7(9):141-156.

Pinar, Musa., Girald, Tulay., and Eser, Zeliha. 2012. Consumer-based brand equity in banking industry. International Journal of Bank Marketing, 30(5):359-375

PT. Sinar Sosro. 2016. Sejarah Perusahaan Sosro. www.sosro.com. (diunduh tanggal 28 April 2017)

Rheisiki. 2016. Minuman Teh Dalam Kemasan yang Berada di Indonesia. www.kaskus.co.id. (diakses pada 9 Agustus 2017)

Shabbir, Chatchai Pitsaphol Rizwan., and Zhang Jing. 2014 The Relationship of Brand Equity Dimensions: A Casestudy of Samsung Brand in Thailand. European Journal of Business and Management, 6(1):182-189. 
Shahin, Arash., Ali Kazemi., Hamseh Kazemi Mahyari. 2012. How Consumer's Perception of Country of Origin Affects Brand Equity: A Case Study in Iran Middle-East. Journal of Scientific Research, 12(6):8-10.

Shimp, T. A. 2014. Komunikasi Pemasaran Terpadu dalam Periklanan dan Promosi. Jakarta: Salemba Empat.

Sigiro, AfrianiCristine., Putri, Yuliani Rachma., Imran, Ayub Ilfandy. 2016. Analisis Faktor Pembentuk Ekuitas Merek Toyota dan Daihatsu di Indonesia. Jurnal Sosioteknologi, 15(3):335-345.

Silaban, Bernard E., dan Marselia, Fitri Andini. 2016. Perbandingan Ekuitas Merek Sepatu Olahraga Nike dan Adidas. Jurnal Esensi, 19(2):84-111.

Soebianto, Albert. 2014. Analisis Pengaruh Faktor-Faktor Brand Equity Sepeda Motor Merek Honda Terhadap Keputusan Pembelian pada Konsumen di Kota Bandung. E-Journal Graduate Unpar, 1(1):14-37.

Sugiyono. 2012. Metode Penelitian Kuantitatif Kualitatif dan R\&D. Bandung: Aalfabeta

Sugiyono. 2014. Metode Penelitian Bisnis (Pendekatan Kuantitatif, Kualitatif, dan $R \& D)$. Bandung: Alfabeta.

Tan, Teok Ming., Liew, Tze Wei., William, Lee Soon Siong., Michelle, Ong Bee Fang., Tan, Su-Mae. 2012. Consumer-based Brand Equity in the Service Shop. International Journal of Marketing Studies, 4(4):60-77.

Teh Pucuk Harum. 2017. Sejarah Perusahaan Mayora. www.tehpucukharum.com (diakses pada 28 April 2017)

Top Brand Award.com. 2017. Fase 1 Kategori: Teh Dalam Kemasan Siap Minum. www.TopBrandAward.com (diakses pada 27 April 2017)

Tong, Xiao., \& Hawley, Jana M. 2009. Measuring customer-based brand equity: empirical evidence from the sportswear market in China. Journal of Product and Brand Management, 18(4):262-271.

Touli, Masjid Nasiri., and Kazemi, Reza Mohammad. 2013. Comparative Study of Brand Equity from Costumers Perspective in Private Bank Industry. International Journal of Management, 1(2):21-26.

Widiananta, Kadek Tresna, dan Made Wardana. 2016. Elemen-Elemen Brand Equity yang Membedakan Produk Olahraga Merek Adidas dengan Nike diKota Denpasar. E-Journal Manajemen Unud. 5(9):5811-5838. 
E-Jurnal Manajemen Unud, Vol. 7, No. 3, 2018: 1339-1367

Wijaya, Andrew., Semuel, Hatante., dan Japarianto, Edwin. 2013. Analisa Pengaruh Perceived Quality terhadap Perceived Value Konsumen Pengguna Internet Mobile XL di Surabaya. Jurnal Manajemen Pemasaran Petra, 1(1):1-12.

Yamin, Sofyan., dan Kurniawan, Hery. 2013. SPSS Complete. Jakarta: Salemba Infotek 